\title{
Basal cell carcinoma with concomitant insignificant adenocarcinoma of the prostate
}

\author{
Takuya Koie - Hayato Yamamoto • \\ Shingo Hatakeyama - Takahiro Yoneyama • \\ Yasuhiro Hashimoto • Chikara Ohyama
}

Received: 9 May 2012/Accepted: 27 August 2012/Published online: 12 October 2012

(C) The Japan Society of Clinical Oncology 2012

\begin{abstract}
Basal cell carcinoma (BCC) of the prostate is a rare tumor, comprising $<0.01 \%$ of all malignant tumors of the prostate. A 75-year-old Japanese man visited a general hospital with acute urinary retention. He underwent a transurethral resection of the prostate. Immunochemical examination revealed that the tumor cells were strongly positive for p63 and high-molecular-weight cytokeratin (34 $\beta$ E12 and CK 5/6). Magnetic resonance imaging indicated that there was no involvement of the bladder neck or periprostatic tissue with the BCC. Retropubic radical prostatectomy was performed. Histological examination revealed insignificant acinar adenocarcinoma in the peripheral zone of the prostate, while BCC was not identified in the specimen. BCC with concomitant adenocarcinoma of the prostate is extremely rare, and has previously been reported in only four cases.
\end{abstract}

Keywords Basal cell carcinoma - Prostate cancer . Malignant tumor of the prostate

\section{Introduction}

Basal cell carcinoma (BCC) of the prostate is a rare tumor, comprising $<0.01 \%$ of all malignant tumors of the prostate [1]. BCC with concomitant adenocarcinoma of the prostate is extremely rare; only four cases have been reported [2].

T. Koie $\cdot$ H. Yamamoto $\cdot$ S. Hatakeyama $\cdot$ T. Yoneyama

Y. Hashimoto $\cdot$ C. Ohyama $(\bowtie)$

Department of Urology, Hirosaki Graduate School of Medicine,

5 Zaifucho, Hirosaki 036-8562, Japan

e-mail: coyama@cc.hirosaki-u.ac.jp
Herein, we report a case of BCC with concomitant adenocarcinoma of the prostate and review the relevant literature.

\section{Case report}

A 75-year-old Japanese man visited a general hospital with acute urinary retention. The prostate was enlarged and firm, with a smooth surface on digital rectal examination. His serum prostate-specific antigen (PSA) level was $2.31 \mathrm{ng} / \mathrm{mL}$. He underwent a transurethral resection of the prostate (TURP). Histological examination revealed a malignant tumor composed of basaloid cells with round nuclei, scant cytoplasm, palisading, and solid nest formation (Fig. 1). Immunochemical examination revealed that the tumor cells were strongly positive for p63 and high-molecular-weight cytokeratin (HMW-CK) (34ßE12 and CK 5/6) (Fig. 2a, b). No staining was seen for PSA, P504S, cytokeratin 7, or cytokeratin 20. On the basis of these findings, the patient was diagnosed with $\mathrm{BCC}$ of the prostate and referred to our hospital for further evaluation.

The cavity of the prostatic urethra was identified on the pelvic magnetic resonance image (Fig. 3). No involvement of the bladder neck or periprostatic tissue with the BCC was detected. Computed tomography did not visualize lymph node enlargement or distant metastases. Retropubic radical prostatectomy (RRP) was performed. Histologically, basal cell hyperplasia $(\mathrm{BCH})$ was seen within the prostate gland and $\mathrm{BCC}$ was not detected in the surgical specimen. Acinar adenocarcinoma of the prostate (Gleason score $4+3$ ) was identified in the peripheral zone of the prostate; the tumor volume was $0.48 \mathrm{~mL}$.

The patient has been followed up for four years and has shown no evidence of local recurrence or distant metastasis 


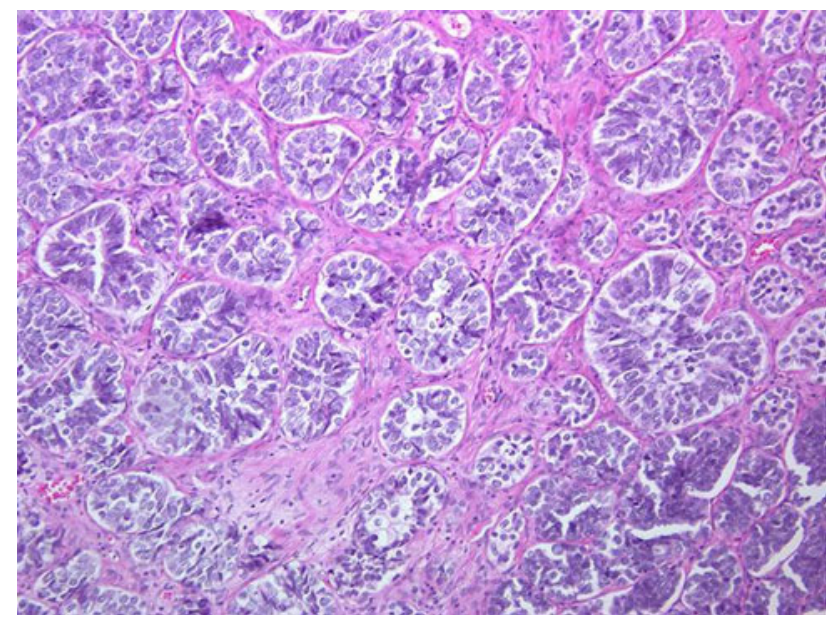

Fig. 1 Hematoxylin-eosin-stained section revealed a malignant tumor composed of basaloid cells with round nuclei, scant cytoplasm, palisading, and solid nest formation $(\times 100)$
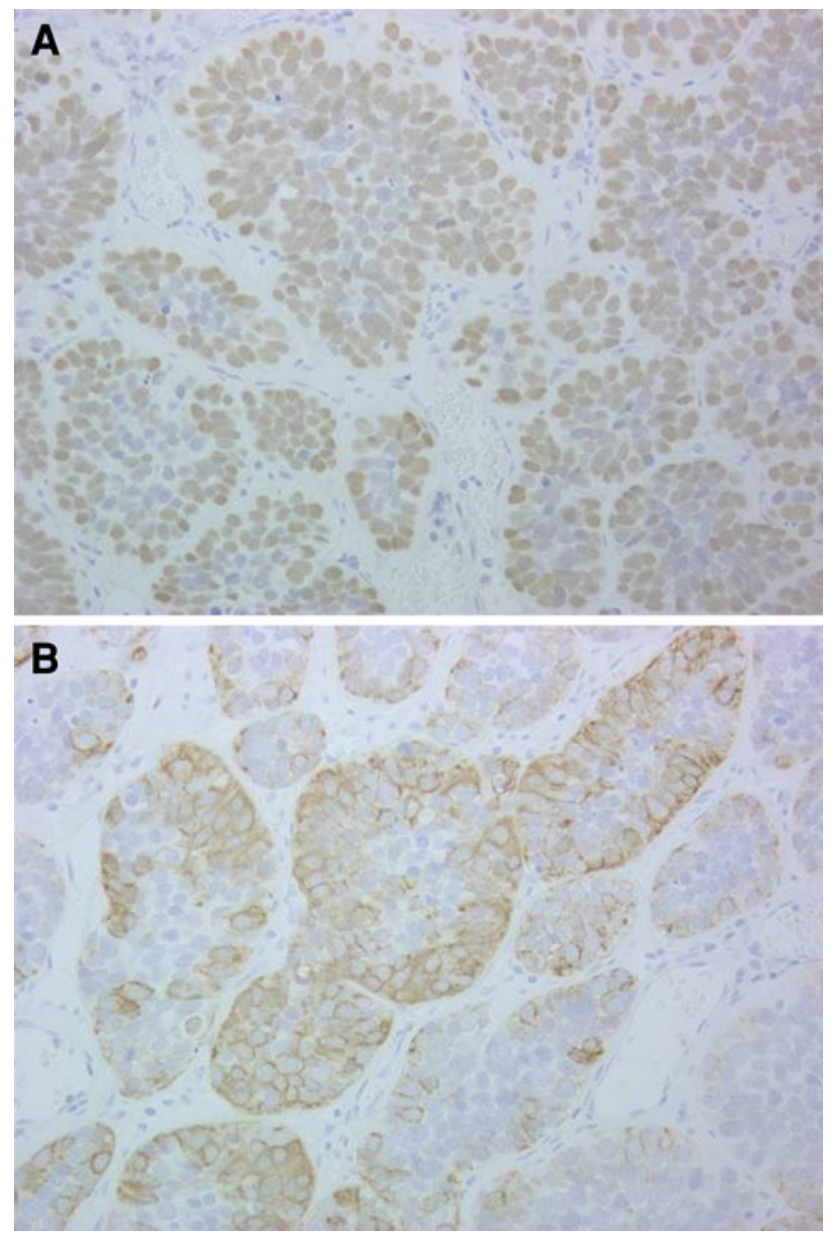

Fig. 2 Immunohistochemical examination showed that the tumor cells were positive for p63 (a) and high-molecular-weight cytokeratin $34 \beta \mathrm{E} 12$ (b) $(\times 200)$

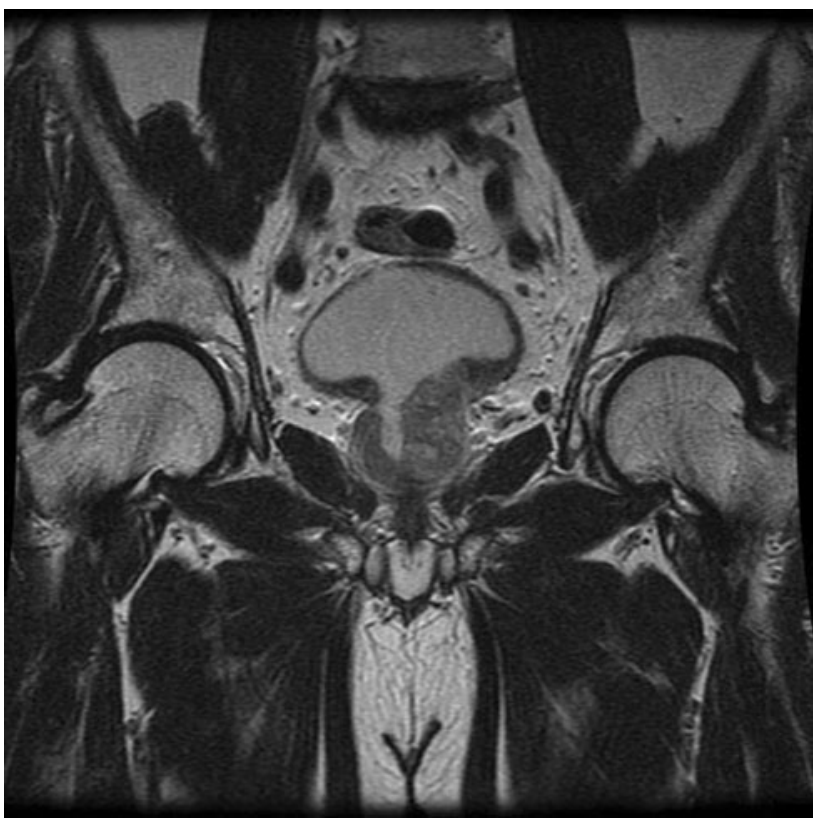

Fig. 3 Magnetic resonance imaging identified the cavity of the prostatic urethra, and no involvement of the bladder neck or periprostatic tissue with the basal cell carcinoma was observed

in that time. The PSA level has remained undetectable during the follow-up period.

\section{Discussion}

Basal cell proliferations $(\mathrm{BCP})$ within the prostate gland usually arise in the transition zone, and are characterized by multiple layers of basal cells in the gland [3]. They are more commonly diagnosed by TURP than by needle biopsies from the peripheral zone [4]. Malignant tumors composed of basal cells are categorized as adenoid cystic carcinoma (ACC)/basal cell carcinoma (BCC) of the prostate [5]. BCC of the prostate includes malignant basaloid proliferations and neoplasms that resemble ACC of the salivary glands [5]. In 2004, the World Health Organization proposed that malignant basal cell tumors of the urinary system and male genital organs should be classified under the single term "BCC" [6].

Immunochemical markers are frequently accessed in cases of BCC. BCCs are usually negative for enzyme markers such as PSA. This feature can be used to distinguish a BCC from a poorly differentiated adenocarcinoma [7]. HMW-CK $34 \beta$ E12 specifically stains normal basal cells and benign basal cell lesions of the prostate [5]. P63 is another marker that stains basal cells and rarely secretory cells when they are poorly differentiated [8]. Shah et al. [8] stated that a combination of $34 \beta \mathrm{E} 12$ and $\mathrm{p} 63$ staining was better for identifying basal cell lesions than $34 \beta \mathrm{E} 12$ or p63 staining alone. 
$\mathrm{BCC}$ is considered to have indolent biological potential and a good prognosis, and requires less aggressive treatment than an acinar adenocarcinoma [7]. However, its biological behavioris still rather uncertain due to a lack of follow-up. Ayyathurai et al. [7] reported that $17 \%$ of patients with ACC died from the disease while none of the patients with BCC died a cancer-related death. On the other hand, five specimens from the seven patients who underwent RRP showed extraprostatic extension of the BCC [2]. Metastasis or local recurrence occurred in $10.3 \%$ of the patients with pure BCC who underwent TURP or RRP [2]. Some tumors show local aggression with involvement of the bladder neck and periprostatic tissue, and metastatic disease to multiple organs [9, 10]. Ali et al. [2] suggested that the predominant basaloid pattern, with a large solid nest and central necrosis, is indicative of an aggressive disease with an adverse outcome. Komura et al. [10] described that three patients $(5.3 \%)$ died of $\mathrm{BCC}$, while one patient $(1.8 \%)$ had a BCC but was still alive.

Overall, a third of the patients were treated with TURP and a third with RRP [7]. Although their biological behavior is not well understood, BCCs have the potential to invade locally, mainly along the nerves, and metastasize distally [7]. Radical surgery may be the first-line management option.

Conflict of interest The authors have no conflict of interest.

\section{References}

1. Tannenbaum M (1975) Adenoid cystic or "salivary gland" carcinomas of prostate. Urology 6:238-239

2. Ali TZ, Epstein JI (2007) Basal cell carcinoma of the prostate: a clinicopathologic study of 29 cases. Am J Surg Pathol 31:697-705

3. Epstein JI, Armas OA (1995) Atypical basal cell hyperplasia of the prostate. Am J Surg Pathol 16:1205-1214

4. Hosler GA, Epstein JI (2005) Basal cell hyperplasia: an unusual diagnostic dilemma on prostate needle biopsies. Hum Pathol 36:480-485

5. Iczkowski KA, Ferguson KL, Grier DD (2003) Adenoid cystic/ basal cell carcinoma of the prostate: clinicopathologic findings in 19 cases. Am J Surg Pathol 27:1523-1529

6. Humphrey PA (2012) Histological variants of prostatic carcinoma and their significance. Histopathology 60:59-74

7. Ayyathurai R, Civantos F, Soloway MS (2007) Basal cell carcinoma of the prostate: current concepts. BJU Int 99:1345-1349

8. Shah RB, Kunju LP, Shen R (2004) Usefulness of basal cell cocktail $(34 \beta \mathrm{E} 12+\mathrm{p} 63)$ in the diagnosis of atypical prostate glandular proliferations. Am J Clin Pathol 122:517-523

9. Segawa N, Tsuji M, Nisida T (2008) Basal cell carcinoma of the prostate: report of a case and review of the published reports. Int $\mathrm{J}$ Urol 15:557-559

10. Komura K, Inamoto T, Tsuji M (2010) Basal cell carcinoma of the prostate: unusual subtype of prostatic carcinoma. Int $\mathrm{J}$ Clin Oncol 15:594-600 